\title{
Effect of Fresh Garlic on Lipid Oxidation and Microbiological Changes of Pork Patties during Refrigerated Storage
}

\author{
Sung Yong Park and Koo Bok Chin* \\ Department of Animal Science and Biotechnology Research Institute, \\ Chonnam National University, Gwangju 500-757, Korea
}

\begin{abstract}
The effects of two levels (1.4 vs 2.8\%) of fresh garlic on lipid oxidation and microbial growth in pork patties were evaluated. Hunter color (L, a, b), pH, thiobarbituric acid reactive substances (TBARS), oxidative volatile compounds, total bacteria and Enterobacteriaceae in the pork patties with or without fresh garlic were measured during storage at $4^{\circ} \mathrm{C}$. Addition of fresh garlic decreased redness (a), while increased $\mathrm{pH}$ and yellowness (b) values of the fresh pork patties were observed, regardless of the levels added. The TBARS values of the pork patties were increased with the addition of fresh garlic $(p<$ $0.05)$. Similar results were observed in oxidative volatile compounds. A total of 13 volatile compounds were detected in the patties (5 sulfur-containing compounds, including allyl mercaptan, allyl methyl sulfide, diallyl sulfide, methyl-(E)-propenyl-disulfide, and diallyl disulfide, and the 8 other oxidative compounds, including 1-pentanol, hexanal, 1-hexanol, heptanal, (E)-2-heptenal, 1-octen-3-ol, (E)-2-octenal and nonanal). Fresh garlic accelerated development of oxidative products in the pork patties, especially hexanal and the total oxidative volatile compounds. However, the addition of 1.4 and $2.8 \%$ of fresh garlic inhibited the growth of total bacteria and Enterobacteriaceae, indicating low total bacterial counts and Enterobacteriaceae than the controls.
\end{abstract}

Keywords: fresh garlic, lipid oxidation, microbial growth, pork patty

\section{Introduction}

Garlic (Allium sativum) contains a number of sulfur and phenolic compounds, which have excellent antioxidant and antimicrobial activity (Corzo-Martinez et al., 2007; Lanzotti, 2006). Sulfur containing compounds are the most characteristic constituents of garlic, especially alliin and allicin. The amino acid, alliin, is the most representative sulfur compound in fresh garlic, and is converted to allicin by alliinase when garlic is crushed (Itakura et al., 2001). Furthermore, the allicin produced is instantly decomposed to other sulfur compounds, such as, dimethyl sulfide, dimethyl disulfide, dially disulfide, dithiines and ajoene (Ali et al., 2000). However, the proportion of these constituents are significantly affected by the methods of preparation during manufacturing, resulting in different pharmacologic activities (Amagase et al., 2001; Kasuga et al., 2001). Grinding garlic bulbs activates allii-

*Corresponding author: Koo Bok Chin, Department of Animal Science and Biotechnology Research Institute, Chonnam National University, Gwangju 500-757, Korea. Tel: +82-62-530-2121, Fax: +82-62-530-2129, E-mail: kbchin@chonnam.ac.kr nase, which converts alliin to allicin, hence fresh garlic includes allicin and its derivaties including diallyl sulfide (DAS), diallyl disulfide (DADS), and diallyl trisulfide (DATS) (Corzo-Martinez et al., 2007). Yin and Cheng (2003) investigated the antioxidant and antimicrobial effects of four garlic-derived organosulfur compounds (diallyl sulfide, diallyl disulfide, $S$-ethyl cysteine, and $n$ acetyl cysteine) in ground beef, and noted that four garlicderived compounds reduced lipid oxidation, and diallyl sulfide and diallyl disulfide having hydrophobic properties inhibited the growth of pathogenic bacteria such as Salmonella Typhimurium, E. coli $\mathrm{O} 157: \mathrm{H7}$, L. monocytogenes, Staphylococcus aureus and Campylobacter jejuni. Sallam et al. (2004) studied the antioxidant and antimicrobial effects of three garlic preparations (fresh garlic, FG; garlic powder, GP; garlic oil, GO) in chicken sausage and found that the antioxidant and antimicrobial effects of FG were greater than those of GP and GO. Furthermore, they suggested that the low antimicrobial activity of GO, as compared to FG or GP, may have been due to the loss of organosulfur compounds during sample preparations.

Allicin possesses good antimicrobial activity against a wide range of Gram-negative and Gram-positive bacteria 
(Ankri and Mirelman, 1999; Astal, 2004). However, allicin acts as a prooxidant, resulting in a significantly increase in TBARS in the $\mathrm{Cu}^{2+}$-induced low density lipoprotein (LDL) oxidation system (Ide et al., 1999; Lau, 2001). Therefore, the objective of this study was to evaluate the potential possibility of using fresh garlic as an agent to control the lipid peroxidation and microbial growth in actual meat products.

\section{Materials and Methods}

\section{Materials and sample preparations}

Fresh pork hams and back fats from the same animal origin of three crossbred pigs [(Landrace $\times$ Yorkshire $) \times$ Duroc, approximately $110 \mathrm{~kg}$ when live] slaughtered the previous day were purchased from a wholesale meat market. Approximately $7 \mathrm{~kg}$ of hams was trimmed to remove the excess fat and connective tissue. After trimming, the pork hams and back fat was ground using a $0.8 \mathrm{~cm}$ plate and grinder (M-12s, Korea Fujee Plant, Korea). Fresh garlic (Allium sativum) was purchased from a local market. The garlic was peeled, washed with dd-water (double distilled water) and wiped them with a towel. Before addition, it was homogenated using a food mixer. Ground ham and back fat was homogenized with $1.5 \% \mathrm{NaCl}$ and fresh garlic (1.4 or $2.8 \%$ ) for 1 min using meat mixer (EF20, Crypto Peerleso LTCL, UK). Then, the mixture was reground using the same grinder and plate, and approximately $80 \mathrm{~g}$ of the mixture was formed into each patty using a petridish. The patties formed were packaged using polystyrene plate with polystyrene lid (130 $\mathrm{mm} \times$ $205 \mathrm{~mm} \times 43 \mathrm{~mm}$, Lotte aluminium Co., Korea) and stored at $4^{\circ} \mathrm{C}$ until analyzed. The formulation for patty manufacture is listed in Table 1.

\section{pH and color measurement}

$\mathrm{pH}$ values were measured by a digital $\mathrm{pH}$-meter (Mettler-Toledo, 340, Switzerland), which was calibrated with a buffer ( $\mathrm{pH} 4$ and 7 ). Ten $\mathrm{g}$ of the pork patties were homogenized with $90 \mathrm{~mL}$ of dd-water for $30 \mathrm{~s}$ using the food mixer. The $\mathrm{pH}$ values were then measured five times and expressed as mean values.

Hunter L (lightness), a (redness) and b (yellowness) values were measured using a Color Reader (CR-10, Minolta Corp., LTD, Japan), and expressed as mean values after five measurements were performed on one patty. The colorimeter was calibrated with white board $(\mathrm{L}=91.28$, $\mathrm{a}=$ $1.25, \mathrm{~b}=-1.35$ ) before using.
Table 1. Formulas of fresh pork patties containing various levels of fresh garlic

\begin{tabular}{ccccc}
\hline \hline \multirow{2}{*}{ Ingredients } & \multicolumn{4}{c}{ Treatments (\%) } \\
\cline { 2 - 5 } & CTL & REF & TRT1 & TRT2 \\
\hline Raw meat & 78.5 & 78.5 & 78.5 & 78.5 \\
Fat & 20.0 & 20.0 & 20.0 & 20.0 \\
Salt & 1.5 & 1.5 & 1.5 & 1.5 \\
BHT & - & 0.01 & - & - \\
Fresh garlic & - & - & 1.4 & 2.8 \\
\hline
\end{tabular}

BHT, butylated hydroxyl toluene; CTL, Control; REF, Reference $(0.01 \%$ BHT); TRT1, $1.4 \%$ fresh garlic; TRT2, $2.8 \%$ fresh garlic.

\section{Thiobarbituric acid reactive substances (TBARS)}

TBARS values were measured using the procedure of Witte et al. (1970). Pork patties ( $20 \mathrm{~g})$ were homogenized with $50 \mathrm{~mL}$ of $20 \%$ trichloroacetic acid (in $2 \mathrm{M}$ phosphoric acid) at 10,000 $\mathrm{g}$ for $2 \mathrm{~min}$ using a homogenizer (AM3, Ace Homogenizer, Nissei, Japan). The resulting slurry was then transferred into a $100 \mathrm{~mL}$ mass cylinder. The slurry was diluted to $100 \mathrm{~mL}$ with dd-water and homogenized. After homogenization approximately $50 \mathrm{~mL}$ was filtered through filter paper (Whatman No. 1, Ø $110 \mathrm{~mm}$ ), then $5 \mathrm{~mL}$ of filtrate was transferred into a test tube and along with $5 \mathrm{~mL}$ of 2-thiobarbituric acid $(0.005 \mathrm{M}$ in ddwater) was added. The test tube was shaken well and kept in a dark room for $15 \mathrm{~h}$. The reactive substances were measured at $530 \mathrm{~nm}$ using a spectrophotometer (UV-Visible Spectrophotometer, UV-1601, Shimadzu, Australia).

\section{Oxidative volatile compounds}

Volatile compounds present in the patties with added fresh garlic were extracted using solid phase microextraction (SPME) technique (Park et al., 2009). The fresh pork patties were homogenized using the food mixer, then the homogenized samples $(10 \mathrm{~g})$ and internal standard $(1 \mu \mathrm{L}$, $200 \mathrm{ppm}$ chlorobenzene in methanol, Supelco, USA) were transferred into a $40 \mathrm{~mL}$ amber screw top vial with a hole cap PTFE/silicone septa (Supelco, USA). Before extraction of the volatile compounds, fiber (75 um, Carboxenpolydimethylsiloxane, Supelco, USA) was conditioned by heating in a gas chromatograph injection port equipped with a flame ionization detector (GC/FID) at $250^{\circ} \mathrm{C}$ for 1 h. Vials were preheated for equilibration at $50^{\circ} \mathrm{C}$ for 10 min, and the SPME fiber for extraction of the volatile compounds was exposed to the headspace above the sample at $50^{\circ} \mathrm{C}$ for $30 \mathrm{~min}$. After injection of SPME fiber into GC/FID injection port, the volatile compounds extracted from the pork patties were isolated from the SPME fiber at $250^{\circ} \mathrm{C}$ for $5 \mathrm{~min}$. Qualitative analysis of the volatile compounds was performed in GC/MS (mass spectrome- 
Table 2. Operation conditions of gas chromatograph and gas chromatograph-mass spectrometry for the analysis of volatile compounds in pork patties

\begin{tabular}{|c|c|}
\hline Type & $\begin{array}{c}\text { Hewlett Packard } 6890 \text { GC-FID } \\
\text { and GC-MS system }\end{array}$ \\
\hline Column (HP-5) & $\begin{array}{c}30 \mathrm{~m} \text { length } \times 0.25 \mathrm{~mm} \text { i.d. } \times 0.1 \mathrm{uL} \\
\text { film thickness }\end{array}$ \\
\hline Detector & $\begin{array}{c}\text { Flame ionization detector (FID) } \\
5973 \text { mass selective detector (MSD) }\end{array}$ \\
\hline Carrier gas & Helium \\
\hline Injector type & Splitless mode \\
\hline Purge flow & $15 \mathrm{~mL} / \mathrm{min}$ \\
\hline Flow rate & $1 \mathrm{~mL} / \mathrm{min}$ \\
\hline Inlet temperature & $250^{\circ} \mathrm{C}$ \\
\hline $\begin{array}{l}\text { Detector } \\
\text { temperature }\end{array}$ & $270^{\circ} \mathrm{C}$ in FID \\
\hline $\begin{array}{l}\text { Oven } \\
\text { temperature }\end{array}$ & $\begin{array}{l}\text { Initial temp.: } 40^{\circ} \mathrm{C} \text {, Initial holding time: } \\
5 \text { min, Rate: } 10^{\circ} \mathrm{C} \mathrm{min}^{-1} \text { until } 270^{\circ} \mathrm{C} \text {, Final } \\
\text { temp.: } 270^{\circ} \mathrm{C} \text {, Final holding time: } 2 \text { min } \\
5973 \text { mass selective detector }\end{array}$ \\
\hline $\begin{array}{l}\text { Ion source } \\
\text { temperature }\end{array}$ & $178^{\circ} \mathrm{C}$ \\
\hline Ionization energy & $70 \mathrm{eV}$ \\
\hline Scan & $2.0 \mathrm{Scans} / \mathrm{s}$ \\
\hline Filament emission & $1 \mathrm{~mA}$ \\
\hline Library & Wiley $77 n$ MS library \\
\hline
\end{tabular}

try). The volatile compounds were then identified by comparison of the retention time with standards such as 1pentanol, hexanal, heptanal, (E)-2-heptenal, 1-octen-3-ol, (E)-2-octenal and nonanal (Sigma-Aldrich, Germany) in GC/FID. The information and operation conditions of GC/FID and GC/MS were same as in Table 2. The quantity of each peak was calculated as follows:

$$
\begin{aligned}
& \text { Quantity }(\mu \mathrm{g} / \mathrm{kg})= \\
& \frac{\text { area of each peak }}{\text { area of internal standard peak }} \times \begin{array}{c}
\text { concentration of diluted } \\
\text { internal standard }(20 \mu \mathrm{g} / \mathrm{kg})
\end{array}
\end{aligned}
$$

\section{Microbial test}

The total plate counts (TPC) and violet red bile (VRB) agar were employed for the determination of total bacterial counts and number of Enterobacteriaceae, respectively (Chin et al., 2006). Ground pork patties (10 g) were homogenized with $90 \mathrm{~mL}$ of sterile dd-water, and serially diluted, and then $0.1 \mathrm{~mL}$ aliquots of each dilution were spread on TPC and VRB agars. The plates were incubated at $37^{\circ} \mathrm{C}$ for $2 \mathrm{~d}$, counted and expressed as Log CFU/g.

\section{Statistical analysis}

The experiment was replicated 3 times, and the data were analyzed using two-way analysis of variance (ANOVA) in
SPSS 14.0 software for Windows. The treatments variables (control, reference (BHT $0.01 \%$ ), with $1.4 \%$ or $2.8 \%$ of fresh garlic) were compared with storage time $(0,3,7$, $10,14,21$ and $28 \mathrm{~d})$ for microbial test, storage time $(0,3$, 7, 10 and $14 \mathrm{~d}$ ) for $\mathrm{pH}$, color and TBARS, or storage time $(0,7$ and $14 \mathrm{~d})$ for the determination of volatile compounds. When interactions between treatment and storage time were not significant $(p>0.05)$, mean separation was also accomplished with pooled means using the Duncan's multiple range test at $0.05 \%$.

\section{Results and Discussion}

Since the interactions between treatment and storage time were not significant $(p>0.05)$ for most parameters, data were pooled by treatment or storage time to test the main effects (Table 3), except for microbial counts and TBARS values.

\section{pH values}

The $\mathrm{pH}$ values were affected by both fresh garlic ( $p<$ $0.001)$ and storage time $(p<0.05)$. The $\mathrm{pH}$ values of treatments and storage time ranged from 5.68 to 5.77 and 5.68 to 5.74 , respectively (Table 3 ). Among the treatments, the $\mathrm{pH}$ values of the fresh pork patties containing $2.8 \%$ of fresh garlic were higher than those of the other $(p<$ $0.001)$. Similar results were found in the previous research of Byun et al. (2001) who studied the effects of garlic on the physicohemical properties of ground pork. They reported that fresh garlic increased the $\mathrm{pH}$ values of both uncooked and cooked ground pork during storage. Similar results were also observed in chicken sausage (Sallam et al., 2004). In addition, Sun et al. (2000) who studied effects of three garlic preparations (fresh garlic, garlic powder and garlic essential oil) on Chinese sausage, reported that fresh garlic treatment only resulted in higher $\mathrm{pH}$ values than the control and other treatments. These results could be attributed to the high $\mathrm{pH}$ value (6.47) of fresh garlic (Ryu et al., 2001).

\section{Hunter colour ( $L$, a and $b)$}

The hunter colour values of the fresh pork patties manufactured with different levels of fresh garlic were measured to estimate the effects of garlic on the colour of the pork patties. The lightness (L) of the pork patties was not affected by any of the treatments, whereas the redness (a) and yellowness (b) of patties with garlic were lower $(p<$ $0.001)$ and higher $(p<0.05)$, respectively in a concentration-dependent manner than those of control groups, res- 
Table 3. Effect of treatment and storage time on $\mathrm{pH}$ and Hunter colour (L, a and b) of pork patties with fresh garlic during storage at $4^{\circ} \mathrm{C}$

\begin{tabular}{|c|c|c|c|c|}
\hline & $\mathrm{pH}$ & $\overline{\mathrm{L}}$ & $\mathrm{a}$ & $\mathrm{b}$ \\
\hline Treatment(T) & $* *$ & NS & $* *$ & $*$ \\
\hline Storage (S) & $*$ & $* *$ & $* *$ & NS \\
\hline $\mathrm{T} * \mathrm{~S}$ & NS & NS & NS & NS \\
\hline \multicolumn{5}{|l|}{ Treatment } \\
\hline Control & $5.70^{\mathrm{bc}} \pm 0.05$ & $56.65 \pm 2.95$ & $7.09^{\mathrm{a}} \pm 2.15$ & $6.77^{c} \pm 1.59$ \\
\hline BHT $0.01 \%$ & $5.68^{\mathrm{c}} \pm 0.04$ & $56.39 \pm 3.03$ & $7.70^{\mathrm{a}} \pm 2.32$ & $7.01^{\mathrm{bc}} \pm 1.61$ \\
\hline Fresh garlic $1.4 \%$ & $5.72^{\mathrm{b}} \pm 0.04$ & $57.06 \pm 3.15$ & $4.30^{\mathrm{b}} \pm 2.22$ & $8.17^{\mathrm{ab}} \pm 1.77$ \\
\hline Fresh garlic $2.8 \%$ & $5.77^{\mathrm{a}} \pm 0.04$ & $58.15 \pm 2.76$ & $2.80^{\mathrm{c}} \pm 1.13$ & $8.52^{\mathrm{a}} \pm 1.49$ \\
\hline \multicolumn{5}{|l|}{ Storage $(\mathrm{d})$} \\
\hline 0 & $5.71^{\mathrm{AB}} \pm 0.05$ & $54.01^{\mathrm{B}} \pm 1.67$ & $8.43^{\mathrm{A}} \pm 2.78$ & $7.32 \pm 1.48$ \\
\hline 3 & $5.68^{\mathrm{B}} \pm 0.07$ & $56.67^{\mathrm{A}} \pm 1.86$ & $6.16^{\mathrm{B}} \pm 2.36$ & $7.02 \pm 1.42$ \\
\hline 7 & $5.72^{\mathrm{AB}} \pm 0.05$ & $57.18^{\mathrm{A}} \pm 2.47$ & $5.18^{\mathrm{C}} \pm 2.49$ & $7.50 \pm 1.63$ \\
\hline 10 & $5.73^{\mathrm{A}} \pm 0.05$ & $58.55^{\mathrm{A}} \pm 3.24$ & $4.23^{\mathrm{D}} \pm 1.98$ & $8.04 \pm 1.92$ \\
\hline 14 & $5.74^{\mathrm{A}} \pm 0.05$ & $58.85^{\mathrm{A}} \pm 2.97$ & $3.36^{\mathrm{E}} \pm 1.59$ & $8.22 \pm 2.18$ \\
\hline
\end{tabular}

${ }^{\mathrm{a}-\mathrm{c}}$ Means with the same letters within a column (for Treatment) are not different $(p>0.05)$.

${ }^{\mathrm{A}-\mathrm{E}}$ Means with the same letters within a column (for storage time) are not different $(p>0.05)$.

Control, control patty; BHT $0.01 \%$, reference patty with BHT (butylated hydroxyl toluene) $0.01 \%$; Fresh garlic $1.4 \%$, patty containing fresh garlic 1.4\%; Fresh garlic $2.8 \%$, patty containing fresh garlic $2.8 \%$; NS, not significant; $*$ indicates $p<0.05 ; * *$ indicates $p<0.001$.

pectively (Table 3). The increases of yellowness and decreases of redness observed in the pork patties containing garlic preparations could be attributed by original color of the fresh garlic, which tended to be yellow. According to Ryu et al. (2004), the yellowness and redness of fresh garlic were 22.11 and -1.29 , respectively. The lightness and redness values of the pork patties increased and decreased with increased storage time, respectively $(p<0.001)$. Based on these results, the lightness and redness were affected by the storage time.

\section{Lipid oxidation by TBARS value}

There was significant interaction between the treatment and storage time for determining the TBARS values of the pork patties $(p<0.001)$ (Fig. 1A). The TBARS values of pork patties significantly increased over the storage time of $14 \mathrm{~d}$. These results could be attributed to the aerobic packaging and grinding procedure used to make the patties. An interesting result was observed in this study. In the most of the previous research, garlic was found to inhibit the lipid peroxidation in various meat products (Sallam et al., 2004; Yin and Cheng, 2003). However, in this study, the fresh garlic was found to act as a potent prooxidant. Thus, patties with fresh garlic had significantly higher TBARS values than the control patties. Prooxidant activities of garlic preparations including fresh garlic were also observed in several previous studies (Borek, 2001; Gazzani et al., 1998). According to Rybak et al. (2004), the amount of allicin in garlic homogenates ranged from 3.2 to $4.8 \mathrm{mg} / \mathrm{g}$ of sample. Ide et al. (1999), who studied the antioxidantive effects of aged garlic extracts, reported that allicin significantly increased oxidation of low density lipoprotein (LDL). Similar results were found by Lau (2001) who reported that allicin increased TBARS in a $\mathrm{Cu}^{2+}$ induced low LDL oxidation system in a concentration-dependent manner. These prooxidant effects of garlic involved $\mathrm{OH} \cdot$ generation and interaction with iron ions (Aruoma et al., 1997). Freeman and Kodera (1995) reported that allicin, which is an intermediate compound with oxidative activity, rapidly oxidized the iron of hemoglobin in blood, hence methemoglobin, which is more active form to lipid peroxidation than hemoglobin, was formed. Hemin loss from met-myoglobin is faster than their reduced form. A number of researchers believe that hemin released from $\mathrm{Hb}$ or $\mathrm{Mb}$ is the primary promoter of lipid oxidation in muscle systems and have proved it through mutation studies (Chiu et al., 1996; Grunwald and Richards, 2006; Richards et al., 2009; Shviro et al., 1982) suggested that hemin's potency as a strong promoter of lipid oxidation might be attributed to its ability to intercalate into phospholipids membranes where it can initiate lipid oxidation in a more suitable environment. Free hemins bind to the membrane lipid by hydrophobic and electrostatic interactions (Cannon et al., 1984; Kirschner-Zilber et al., 1982). In meat products, no effect of fresh garlic on lipid peroxidation was observed from the addition of garlic by Sun et al. (2000) who reported that the addition of fresh garlic to Chinese sausage did not 

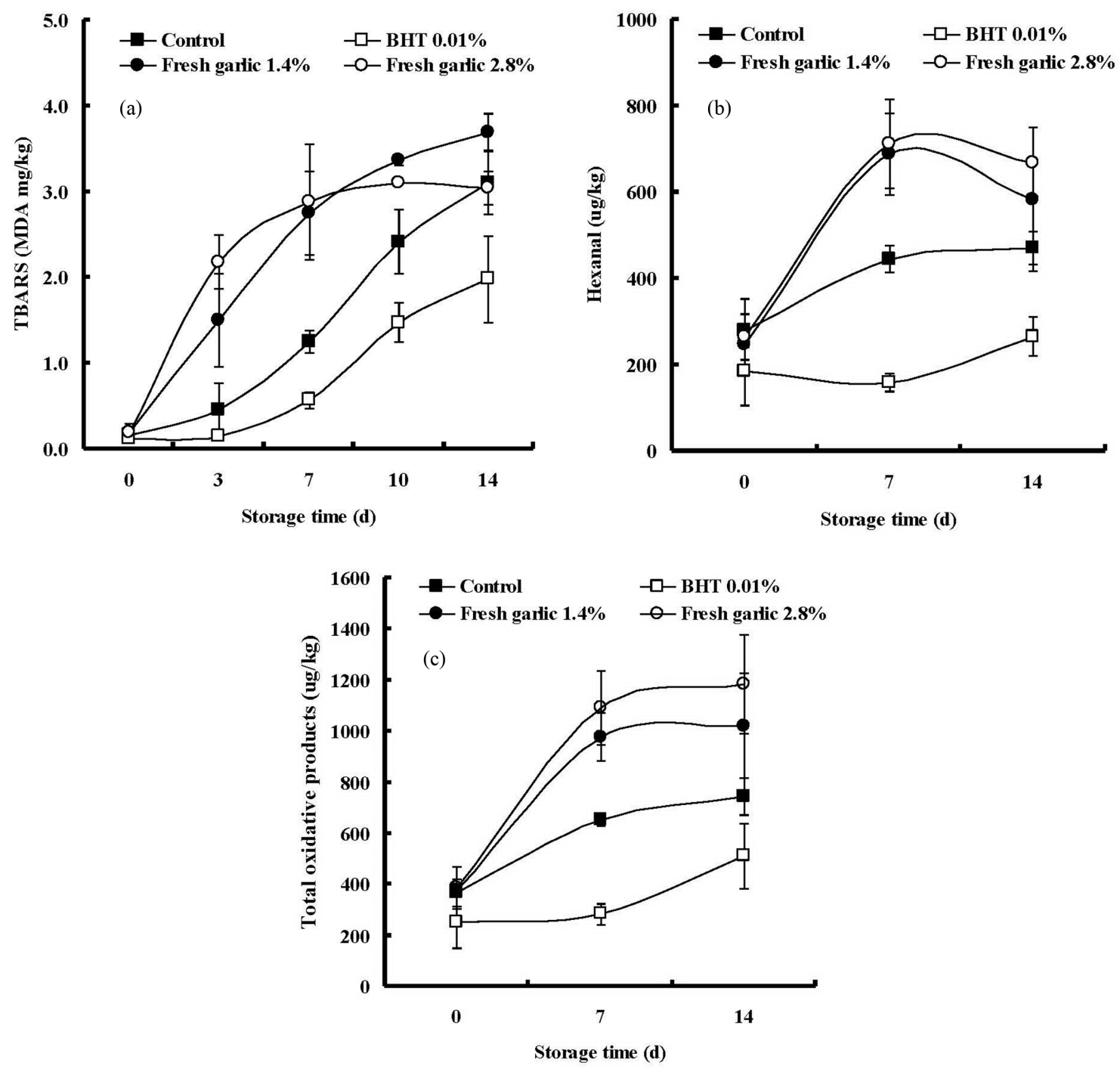

Fig. 1. Changes of thiobarbituric acid reactive substances (TBARS), hexanal and total oxidative products in pork patties as affected by treatment (two levels of fresh garlic) and storage time. (A) TBARS, (B) Hexanal, (C) Total oxidative products; Control, control patty without fresh garlic; BHT $0.01 \%$, reference patty with BHT (butylated hydroxyl toluene, $0.01 \%$ ); Fresh garlic $1.4 \%$, patty containing fresh garlic (1.4\%); Fresh garlic $2.8 \%$, patty comtaining fresh garlic $(2.8 \%)$.

result in lower TBARS values. In addition, similar results in the amount of hexanal and total oxidative products were observed (Fig. 1B and C). As shown in Fig. 1B and $\mathrm{C}$, marked increases of hexanal and total oxidative products were found in pork patties containing fresh garlic. These results supported that fresh garlic accelerated the lipid peroxidation in the fresh pork patties during refrigerated storage.

\section{Sulfur-containing compounds and oxidative vola- tile compounds}

Table 4 lists the volatile compounds extracted from the fresh pork patties manufactured with fresh garlic. As shown in Table 4, a total of 13 volatile compounds were detected in the patties; 5 sulfur-containing compounds, including allyl mercaptan, allyl methyl sulfide, diallyl sulfide, methyl-(E)-propenyl-disulfide, and diallyl disulfide, along with 8 other compounds, including 1-pentanol, hexanal, 1-hexanol, heptanal, (E)-2-heptenal, 1-octen-3-ol, (E)-2-octenal and nonanal. All of the organosulfur compounds have been previously suggested as volatile compounds which could be derived from garlic (Calvo-Gomez et al., 2004; Shin et al., 1999; Yu et al., 1989). There were no significant interactions between treatment and storage time in any of the detected compounds, except for hexanal (Table 4). All sulfur-containing compounds showed significant differences as compard to other treatments $(p<$ 0.001 ) because these compounds were not detected in the 
Table 4. Summary of interactions and main effects of sulfur-containing compounds and oxidative products in pork patties as affected by treatment (fresh garlic) and storage time during storage at $4^{\circ} \mathrm{C}$

\begin{tabular}{|c|c|c|c|}
\hline \multirow{2}{*}{ Compounds } & \multirow{2}{*}{$\begin{array}{c}\text { Interactions } \\
\text { Treatment*Storage time }\end{array}$} & \multicolumn{2}{|c|}{ Main effects } \\
\hline & & Treatment & Storage time \\
\hline \multicolumn{4}{|l|}{ Sulfur-containing compounds } \\
\hline allyl mercaptan & NS & $* *$ & $*$ \\
\hline allyl methyl sulfide & NS & $* *$ & NS \\
\hline diallyl sulfide & NS & $* *$ & NS \\
\hline methyl-(E)-propenyl-disulfide & NS & $* *$ & NS \\
\hline diallyl disulfide & NS & $* *$ & NS \\
\hline Total & NS & $* *$ & $*$ \\
\hline \multicolumn{4}{|l|}{ Oxidative compounds } \\
\hline 1-pentanol & NS & NS & $* *$ \\
\hline hexanal & $* *$ & $* *$ & $* *$ \\
\hline 1-hexanol & NS & $*$ & $* *$ \\
\hline heptanal & NS & NS & $*$ \\
\hline (E)-2-heptenal & NS & $* *$ & $*$ \\
\hline 1-octen-3-ol & NS & NS & $*$ \\
\hline (E)-2-octenal & NS & $* *$ & $*$ \\
\hline nonanal & NS & $* *$ & NS \\
\hline Total & $* *$ & $* *$ & $* *$ \\
\hline
\end{tabular}

NS, not significant; * indicates $p<0.05 ; * *$ indicates $p<0.001$.

Table 5. Effects of treatment (fresh garlic) and storage time on sulfur-containing compounds and oxidative products detected in pork patties during storage at $4^{\circ} \mathrm{C}$

\begin{tabular}{|c|c|c|c|c|c|c|c|c|c|}
\hline \multirow{4}{*}{ Compounds } & \multicolumn{9}{|c|}{ Content $\left(\mu \mathrm{g} \mathrm{kg}^{-1}\right)$} \\
\hline & \multicolumn{4}{|c|}{ Treatments } & \multirow{3}{*}{ SEM } & \multicolumn{3}{|c|}{ Storage time $(\mathrm{d})$} & \multirow{3}{*}{ SEM } \\
\hline & \multirow{2}{*}{$\mathrm{CON}$} & \multirow{2}{*}{ BHT } & \multicolumn{2}{|c|}{ Fresh garlic } & & \multirow{2}{*}{0} & \multirow{2}{*}{7} & \multirow{2}{*}{14} & \\
\hline & & & $1.4 \%$ & $2.8 \%$ & & & & & \\
\hline \multicolumn{10}{|l|}{ Sulfur-containing compounds } \\
\hline allyl mercaptan & $-{ }^{c}$ & $-^{c}$ & $361^{\mathrm{b}}$ & $753^{\mathrm{a}}$ & 63.3 & $437^{\mathrm{A}}$ & $227^{\mathrm{B}}$ & $174^{\mathrm{C}}$ & 54.8 \\
\hline allyl methyl sulfide & $-{ }^{b}$ & $-{ }^{b}$ & $77^{\mathrm{a}}$ & $89^{\mathrm{a}}$ & 13.4 & 58 & 62 & 28 & 11.6 \\
\hline diallyl sulfide & $-{ }^{c}$ & $-{ }^{c}$ & $76^{\mathrm{b}}$ & $142^{\mathrm{a}}$ & 17.1 & 78 & 52 & 34 & 14.8 \\
\hline methyl-(E)-propenyl-disulfide & $-{ }^{c}$ & $-^{c}$ & $21^{\mathrm{b}}$ & $34^{\mathrm{a}}$ & 3.0 & 15 & 15 & 11 & 2.6 \\
\hline diallyl disulfide & $-{ }^{c}$ & $-{ }^{c}$ & $152^{\mathrm{b}}$ & $289^{\mathrm{a}}$ & 30.1 & 102 & 113 & 116 & 26.0 \\
\hline Total & $--^{c}$ & $--^{c}$ & $688^{b}$ & $1308^{\mathrm{a}}$ & 91.8 & $690^{A}$ & $469^{\mathrm{AB}}$ & $362^{\mathrm{B}}$ & 80 \\
\hline \multicolumn{10}{|l|}{ Oxidative compounds } \\
\hline 1-pentanol & 54 & 60 & 58 & 71 & 8.0 & $29^{\mathrm{B}}$ & $76^{\mathrm{A}}$ & $77^{\mathrm{A}}$ & 7.0 \\
\hline hexanal & $399^{\mathrm{b}}$ & $203^{\mathrm{c}}$ & $506^{\mathrm{a}}$ & $548^{\mathrm{a}}$ & 24.5 & $244^{\mathrm{B}}$ & $497^{\mathrm{A}}$ & $500^{\mathrm{A}}$ & 21.2 \\
\hline 1-hexanol & $49^{\mathrm{b}}$ & $42^{\mathrm{b}}$ & $109^{\mathrm{ab}}$ & $135^{\mathrm{a}}$ & 24.7 & $17^{\mathrm{B}}$ & $57^{\mathrm{B}}$ & $178^{\mathrm{A}}$ & 21.4 \\
\hline heptanal & 45 & 21 & 47 & 53 & 9.3 & $18^{\mathrm{B}}$ & $52^{\mathrm{A}}$ & $55^{\mathrm{A}}$ & 8.1 \\
\hline (E)-2-heptenal & $6^{\mathrm{b}}$ & $1^{\mathrm{b}}$ & $13^{\mathrm{a}}$ & $15^{\mathrm{a}}$ & 2.2 & $5^{\mathrm{B}}$ & $11^{\mathrm{AB}}$ & $10^{\mathrm{AB}}$ & 1.9 \\
\hline 1-octen-3-ol & 19 & 14 & 26 & 26 & 3.7 & $15^{\mathrm{B}}$ & $29^{\mathrm{A}}$ & $20^{\mathrm{AB}}$ & 3.2 \\
\hline (E)-2-octenal & $4^{c}$ & $3^{\mathrm{c}}$ & $10^{\mathrm{b}}$ & $14^{\mathrm{a}}$ & 1.3 & $5^{\mathrm{B}}$ & $9^{\mathrm{A}}$ & $9^{\mathrm{A}}$ & 1.1 \\
\hline nonanal & $11^{\mathrm{b}}$ & $7^{\mathrm{b}}$ & $22^{\mathrm{a}}$ & $27^{\mathrm{a}}$ & 2.5 & $12^{\mathrm{B}}$ & $17^{\mathrm{AB}}$ & $20^{\mathrm{A}}$ & 2.2 \\
\hline Total & $588^{b}$ & $349^{\mathrm{c}}$ & $792^{a}$ & $888^{\mathrm{a}}$ & 37.7 & $346^{\mathrm{C}}$ & $752^{\mathrm{B}}$ & $865^{\mathrm{A}}$ & 32.6 \\
\hline
\end{tabular}

${ }^{\mathrm{a}-\mathrm{c}}$ Means with same letters within same row (treatment) are not different $(p>0.05)$.

${ }^{A-C}$ Means with same letters within same row (storage time) are not different $(p>0.05)$.

CON, control patty; BHT, reference patty with BHT (butylated hydroxyl toluene) $0.01 \%$; Fresh garlic $1.4 \%$, patty with fresh garlic $1.4 \%$; Fresh garlic $2.8 \%$, patty with fresh garlic $2.8 \%$; -, trace amount.

patties without garlic (Table 5). The results of quantitative analysis of volatile compounds identified from patties with fresh garlic are shown in Table 5. As mentioned above, sulfur-containing compounds were only detected in the patties with garlic, regardless of levels, of which allyl mercaptan and diallyl disulfide were the major sulfur-containing compounds. Alliin derived from $\gamma$-L-glutamyl-S(2-propenyl)-L-cysteine in fresh garlic generates sulfenic 
acids via an enzymatic reaction catalyzed by alliinase. These intermediates immediately produce thiosulfinates such as allicin, which elicits a variety of sulfur compounds, including diallyl sulfide, diallyl disulfide and diallyl trisulfide, due to their instability (Lanzotti, 2006). In fresh pork patties, the addition of fresh garlic increased the amount of sulfur-containing compounds in a concentration-dependent manner. The allyl mercaptan significantly decreased with increased storage time due to its higher volatility, resulting in decreased concentration of the total sulfur-containing compounds. These results might be partially due to the aerobic packaging used, which allows relatively easy to loss of volatile compounds. In contrast with the results of sulfur-containing compounds, all oxidative products significantly increased with increased storage time. This indicated that lipid peroxidation progressed with the oxidation of fat or fatty acids. Thus, the amounts of oxidative products increased with the addition of 1.4 and $2.8 \%$ of fresh garlic. In a previous study, Ahn et al. (1998) reported that hexanal and total volatile compounds in cooked meats were highly associated with lipid oxidation, which was correlated with the TBARS values. Additionally, Brunton et al. (2000) reported the correlation between the TBARS values and aldehyde compounds derived from n-6 fatty acids, and also finding a high correked turkey meat. Based on the previous results, the fresh garlic in the present study accelerated the lipid peroxidation in the fresh pork patties.

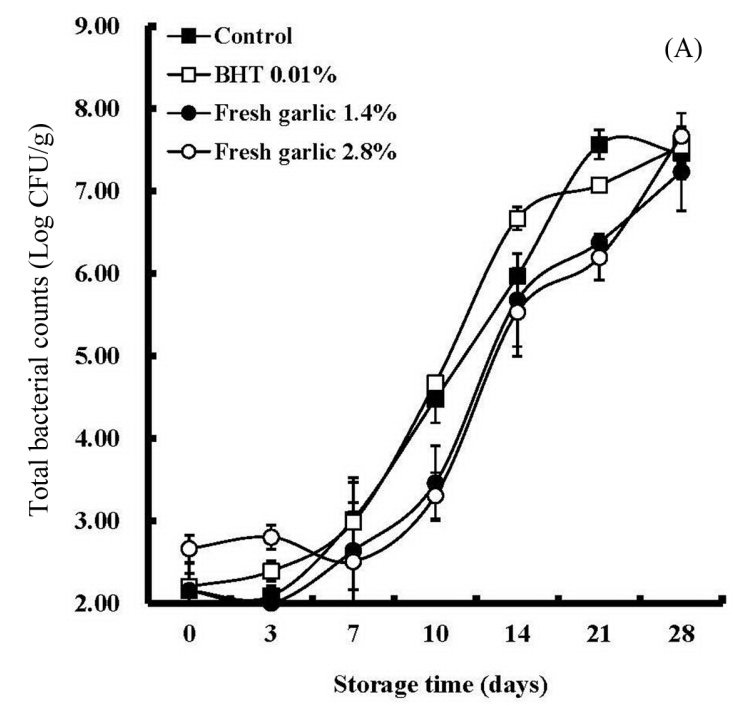
lation of hexanal $\left(r^{2}=0.994\right)$ with TBARS values of coo-

\section{Microbial counts during storage}

Total bacterial counts and number of Enterobacteriaceae in the pork patties with or without fresh garlic are shown in Fig. 2A and B, respectively. Total bacterial counts were lower in the patties containing 1.4 and $2.8 \%$ of fresh garlic than the control. In addition, fresh garlic also showed potent antimicrobial effects against Enterobacteriaceae. As shown in Fig. 2B, the microbial counts for Enterobacteriaceae in pork patties without fresh garlic showed the growth of $>7 \mathrm{Log} \mathrm{CFU} / \mathrm{g}$ at $28 \mathrm{~d}$ of storage, whereas, pork patties with fresh garlic demonstrated growth $<6 \mathrm{Log}$ CFU/g at 28 d of storage. Sallam et al. (2004) reported that antimicrobial effects of the fresh garlic were the best out of three preparations tested, followed by garlic powder and garlic oil, and suggested that the low activity of garlic oil and garlic powder in comparison with fresh garlic might be due to the losses of organosulfur compounds during sample preparations. However, according to the results of Benkeblia (2004), the essential oil extracts of garlic had a marked antibacterial activity against certain pathogens, including Staphylococcus aureus, Salmomella Enteritidis, Aspergillus niger, Penicillium cyclopium, and Fusarium oxysporum. Among the organosulfur compounds derived from garlic, the hydrophobic compounds, diallyl sulfide and diallyl disulfide were found to inhibit the growth of pathogenic bacteria such as S. typhimurium, E. coli $\mathrm{O} 157: \mathrm{H} 7$, L. monocytogenes, $S$. aureus and $C$. jejuni inoculated in ground beef (Yin and Cheng, 2003). The antimicrobial activities of the pork patties containing

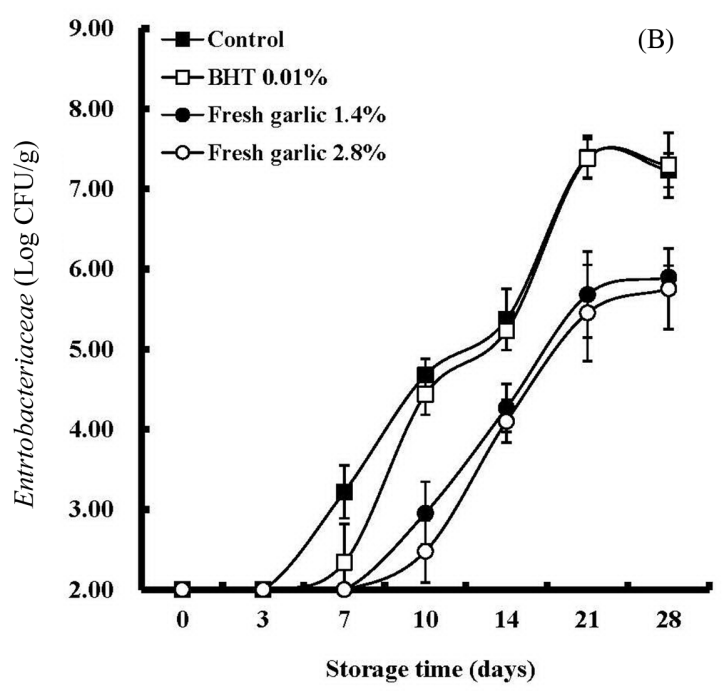

Fig. 2. Changes in total plate counts and Enterobacteriaceae in pork patties as affected by treatment (two levels of fresh garlic) and storage time. (A) Total plate counts, (B) Enterobacteriaceae; Control, control patty without fresh garlic; BHT $0.01 \%$, reference patty with BHT (butylated hydroxyl toluene, $0.01 \%$ ); Fresh garlic $1.4 \%$, patty containing fresh garlic (1.4\%); Fresh garlic $2.8 \%$, patty containing fresh garlic $(2.8 \%)$. 
fresh garlic might be partially due to allicin, which has a potent antimicrobial activity. Allicin, one of the active compounds of freshly crushed garlic homogenates is know to have antibacterial activity against a wide range of Gram-negative and Gram-positive bacteria. Antimicrobial activities of allicin are mainly due to its chemical reaction with thiol-containing enzymes such as thioredoxin reductase, RNA polymerase, and alcohol dehydrogenase (Ankri and Mirelman, 1999). According to Fujisawa et al. (2008) who studied the biological and chemical stability of garlic-derived allicin, the growth of $E$. coli and $S$. aureus were dose-dependently inhibited by the addition of allicin. Garlic juice or aqueous extract from fresh garlic, both of which include a large amount of allicin are known to have high antibacterial effects against many pathogenic bacteria and bacteria causing food poisoning including the following; $S$. aureus, S. saprophyticus, Streptococcus pneumonia, Enterococcus faecalis, E. coli, Enterobacter cloacae, Klebsiella pneumonia, Proteus mirabilis, Pseudomonas aeruginosa, Acinetobacter haemolyticus, Bacillus cereus, Clostridium perfringens, Salmonella, Shigella and L. monocytogenes (Astal, 2004; Bakri and Douglas, 2005; Banerjee and Sarkar, 2003; Chung et al., 2003; Kim et al., 2003).

\section{Conclusions}

Patties with fresh garlic (1.4 and 2.8\%) were oxidized faster than the control patties. In addition, fresh garlic accelerated the development of oxidative products in pork patties, especially hexanal and the total oxidative volatile compounds. Addition of up to $2.8 \%$ of fresh garlic showed antimicrobial activities in pork patties. This study suggest that antioxidative activities of garlic might depend on the type and level of an added garlic, and fresh garlic will be useful as a natural antimicrobial agent with additional antioxidants which can inhibit prooxidative activities of fresh garlic, in meat products.

\section{References}

1. Ahn, D. U., Olson, D. G., Lee, J. I., Jo, C., Wu, C., and Chen, X. (1998) Packaging and irradiation effects on lipid oxidation and volatiles in pork patties. J. Food Sci. 63, 15-19.

2. Ali, M., Thomson, M., and Afzal, M. (2000) Garlic and onions: their effect on eicosanoid metabolism and its clinical relevance. Prostaglandins, Leukotrience, and Essential Fatty Acids, 62, 55-73.

3. Amagase, H., Petesch, B. L., Matsuura, H., Kasuga, S., and Itakura, Y. (2001) Intake of garlic and its bioactive compo- nents. J. Nutr. 131, 955S-962S.

4. Ankri, S. and Mirelman, D. (1999) Antimicrobial properties of allicin from garlic. Microbes and Infection, 2, 125-129.

5. Aruoma, O. I., Spencer, J. P. E., Warren, D., Jenner, P., Butler, J., and Halliwell, B. (1997) Characterization of food antioxidants, illustrated using commercial garlic and ginger preparations. Food Chem. 60, 149-156.

6. Astal, Z. E. (2004) The inhibitory action of aqueous garlic extract on the growth of certain pathogenic bacteria. European Food Res. Technol. 218, 460-464.

7. Bakri, I. M. and Douglas, C. W. I. (2005) Inhibitory effect of garlic extract on oral bacteria. Arch. Oral Biol. 50, 645-651.

8. Banerjee, M. and Sarkar, P. K. (2003) Inhibitory effect of garlic on bacterial pathogens from spices. World J. Microbiol. Biotechnol. 19, 565-569.

9. Benkeblia, N. (2004) Antimicrobial activity of essential oil extracts of various onions (Allium cepa) and garlic (Allium sativum). LWT-Food Sci. Technol. 37, 263-268.

10. Borek, C. (2001) Antioxidant health effects of aged garlic extract. J. Nutr. 131, 1010S-1015S.

11. Brunton, N. P., Cronin, D. A., Monahan, F. J., and Durcan, R. (2000) A comparison of solid-phase microextraction (SPME) fibres for measurement of hexanal and pentanal in cooked turkey. Food Chem. 68, 339-345.

12. Byun, P. H., Jung, J. H., Kim, W. J., and Yoon, S. K. (2001) Effects of garlic addition on lipid oxidation of ground pork during storage. Korean J. Soc. Food Cookery Sci. 17, 117122.

13. Calvo-Gomez, O., Morales-Lopez, J., and Lopez, M. G. (2004) Solid-phase microextraction-gas chromatographic-mass spectrometric analysis of garlic oil obtained by hydrodistillation. J. Chromatogr. A, 1036, 91-93.

14. Cannon, J. B., Kuo, F. S., Pasternack, R. F., Wong, N. M., and Muller-Eberhard, U. (1984) Kinetics of the interaction of hemin liposomes with heme binding proteins. Biochem. 23, 3715-3721.

15. Chin, K. B., Kim, K. H., and Lee, H. C. (2006) Physico-chemical and textural properties, and microbial counts of meat products sold at Korean markets. Korean J. Food Sci. An. 26, 98-105.

16. Chiu, D. T. Y., Van Den Berg, J., Kuypers, F. A., Hung, I. J., Wei, J. S., and Liu, T. Z. (1996) Correlation of membrane lipid peroxidation with oxidation of hemoglobin variants: Possibly related to the rates of hemin release. Free Radical Biol. Med. 21, 89-95.

17. Chung, K. S., Kim, J. Y., and Kim, Y. M. (2003) Comparison of antibacterial activities of garlic juice and heat-treated garlic juice. Korean J. Food Sci. Technol. 35, 540-543.

18. Corzo-Martinez, M., Corzo, N., and Villamiel, M. (2007) Biological properties of onions and garlic. Trends. Food Sci. Technol. 18, 609-625.

19. Freeman, F. and Kodera, Y. (1995) Garlic chemistry: Stability of S-(2-propenyl)-2-propene-1-sulfinothioate (Allicin) in blood, solvents, and simulated physiological fluids. J. Agric. Food Chem. 43, 2332-2338.

20. Fujisawa, H., Suma, K., Origuchi, K., Kumagai, H., Seki, T., and Ariga, T. (2008) Biological and chemical stability of gar- 
lic-derived allicin. J. Agric. Food Chem. 56, 4229-4235.

21. Gazzani, G., Papetti, A., Massolini, G., and Daglia, M. (1998) Anti-and prooxidant activity of water soluble components of some common diet vegetables and the effect of thermal treatment. J. Agric. Food Chem. 46, 4118-4122.

22. Grunwald, E. W. and Richards, M. P. (2006) Studies with myoglobin variants indicate that released hemin is the primary promoter of lipid oxidation in washed fish muscle. J. Agric. Food Chem. 54, 4452-4460.

23. Ide, N., Lau, B. H. S., Ryu, K., Matsuura, H., and Itakura, Y. (1999) Antioxidant effects of fructosyl arginine, a Maillard reaction product in aged garlic extract. J. Nutr. Biochem. 10, 372-376.

24. Itakura, Y., Ichikawa, M., Mori, Y., Okino, R., Udayama, M., and Morita, T. (2001) How to distinguish garlic from the other Allium vegetables. J Nutr. 131, 963S-967S.

25. Kasuga, S., Uda, N., Kyo, E., Ushijima, M., Morihara, N., and Itakura, Y. (2001) Pharmacologic activities of aged garlic extract in comparison with other garlic preparations. J. Nutr. 131, 1080S-1084S.

26. Kim, M. H., Kim, S. Y., Shin, W. S., and Lee, J. S. (2003) Antimicrobial activity of garlic juice against Escherichia coli O157:H7. Korean J. Food Sci. Technol. 35, 752-755.

27. Kirschner-zilber, I., Rabizadeh, E., and Shaklai, N. (1982) The interaction of hemin and bilirubin with the human red cell membrane. Biochimica et Biophysica Acta, 690, 20-30.

28. Lanzotti, V. (2006) The analysis of onion and garlic. J. Chromatogr. $A, 1112,3-22$.

29. Lau, B. H. S. (2001) Suppression of LDL oxidation by garlic. J. Nutr. 131, 985S-988S.

30. Park, S. Y., Yoon, Y. M., Schilling, M. W., and Chin, K. B. (2009) Evaluation of volatile compounds isolated from pork loin (Longissimus dorsi) as affected by fiber type of solidphase microextraction (SPME), preheating and storage time. Korean J. Food Sci. An. 29, 579-589.

31. Richards, M. P., Cai, H., and Grunwald, E. W. (2009) Pheny- lalanine substitution at site B10 (L29F) inhibits metmyoglobin formation and myoglobin-mediated lipid oxidation in washed fish muscle: Mechanistic implications. J. Agric. Food Chem. 57, 7997-8002.

32. Rybak, M. E., Calvey, E. M., and Harnly, J. M. (2004) Quantitative determination of allicin in garlic: supercritical fluid extraction and standard addition of alliin. J. Agric. Food Chem. 52, 682-687.

33. Ryu, H. J., Choi, E. J., and Oh, M. S. (2004) Changes in quality characteristics of chopped garlic with various storage method. Korean Home Economics Assoc. 42, 167-180.

34. Ryu, K., Ide, N., Matsuura, H., and Itakura, Y. (2001) No-(1deoxy-D-frectos-1-yl)-L-arginine, an antioxidant compound identified in aged garlic extract. J. Nutr. 131, 972S-976S.

35. Sallam, K. I., Ishioroshi, M., and Samejima, K. (2004) Antioxidant and antimicrobial effects of garlic in chicken sausage. LWT-Food Sci. Technol. 37, 849-855.

36. Shin, D. B., Seog, H. M., Kim, J. H., and Lee, Y. C. (1999) Flavor composition of garlic from different area. Korea J. Food Sci. Technol. 31, 293-300.

37. Shviro, Y., Zilber, I., and Shaklai, N. (1982) The interaction of hemoglobin with phosphatidylserine vesicles. Biochimica et Biophysica Acta, 687, 63-70.

38. Sun, Y. M., Ockerman, H. W., and Marriott, N. G. (2000) Garlic in Chinese sausage. J. Muscle Foods, 11, 35-43.

39. Witte, V. C., Krause, G. F., and Bailey, M. E. (1970) A new extraction method for determining 2-thiobarbituric acid values of pork and beef during storage. J. Food Sci. 35, 582585.

40. Yin, M. C. and Cheng, W. S. (2003). Antioxidant and antimicrobial effects of four garlic-derived organosulfur compounds in ground beef. Meat Sci. 63, 23-28.

41. Yu, T. H., Wu, C. M., and Liou, Y. C. (1989) Effects of pH adjustment and subsequent heat treatment on the formation of volatile compounds of garlic. J. Food Sci. 54, 632-635.

(Received 2014.5.27/Revised 2014.8.26/Accepted 2014.8.26) 